$\begin{array}{ll}\text { REVISTA } & \text { CRIANCAS: } \\ \text { DA } \\ \text { FUNDARTE }\end{array}$

\title{
A CRIANÇA E O TEXTO LITERÁRIO
}

Thania Teixeira Asinelli

DOI: $10.19179 / 2319-0868.802$ 


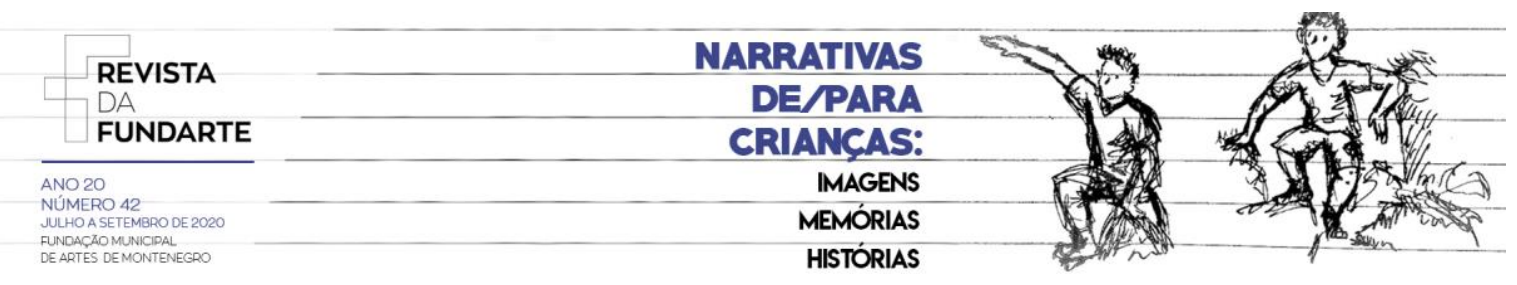

A CRIANÇA E O TEXTO LITERÁRIO

Thania Teixeira Asinelli ${ }^{1}$

Resumo: Esta abordagem incide sobre a incontestável importância da Literatura, cujos estudos, debates e retórica vêm ocupando espaço considerável no discurso acadêmico, na mídia e nos organismos governamentais, porém, ainda longe de ações efetivas (salvo práticas pontuais), no ambiente escolar. A criança, ser ávido de fantasias e curiosidades, dotada de imaginação fértil, tem direito absoluto à literatura como instrumento de sensibilização, deleite e descobertas. A recepção da criança ao texto literário implica um trabalho com gama variada e seleção criteriosa desse gênero textual, o que requer envolvimento do professor leitor, bem como o entendimento de que a obra literária não está sujeita às normas e regras, nem ao compromisso de ensinamentos dos aspectos gramaticais da língua. $O$ universo dos textos poéticos amplia o imaginário e vai além da compreensão rasa e normatizada, como toda a obra de arte sugere.

Palavras-chaves: Criança; Professor; Texto literário.

\section{THE CHILD AND THE LITERARY TEXT}

Abstract: This approach focuses on the undeniable importance of literature, whose studies, debates and rhetoric have been occupying considerable space in academic discourse, in the media and in government agencies, but still far from effective actions (except for specific practices) in the school environment. The child, being eager for fantasies and curiosities, endowed with fertile imagination, has an absolute right to literature as an instrument of sensitization, delight and discovery. The child's reception of the literary text implies a work with varied range and careful selection of this textual genre, which requires the involvement of the reading teacher, as well as the understanding that the literary work is neither subject to the norms and rules, nor the commitment of teachings on the grammatical aspects of the language. The universe of poetic texts expands the imaginary and goes beyond the shallow and normalized understanding, as the whole work of art suggests.

Key words: Child; Teacher; Literary text.

\section{L'ENFANT ET LE TEXTE LITTÉRAIRE}

RESUMÉ: Cette approche touche l'incontestable importance de la littérature, dont les études, débat et réthorique occupent depuis un certain temps une place considérable dans les discussions académiques, les médias et aussi dans les organismes gouvernementaux, et pourtant, encore loin des actions effectives (sauf quelques mises en pratiques) dans l'environnement scolaire. L'enfant, avide de fantaisie et curiosités et qui déborde l'imagination, a le droit absolu à la littérature comme outil de sensibilisation, plaisir et découvertes. L'accès de l'enfant au texte littéraire exige un travail d'une gamme variée et d'une sélection appropriée de ce genre textuel, ce qui demande l'engagement du professeur lecteur mais aussi la compréhension que l'oeuvre littéraire ne peut pas être soumise à des normes ou règles et qu'elle n'a pas l'obligation

\footnotetext{
1 Doutora em Educação pela Universidade René Descartes / Paris V - Sorbonne (França)

Pós doutoranda em Educação da Infância Universidade do Minho (Braga/Portugal)

Socióloga pela Universidade Católica do Paraná (Brasil)

Palestrante na área de Educação - Formação de Professores

Autora de livros didáticos

Letra Consultoria Educacional Ltda. Curitiba/PR/Brasil
}

ASINELLI, Thania Teixeira. A criança e o texto literário. Revista da FUNDARTE. Montenegro, p.01-16, ano 20, no 42, julho/setembro de 2020.

Disponível em: http://.seer.fundarte.rs.gov.br/index.php/RevistadaFundarte/index> 30 de setembro de 2020. 


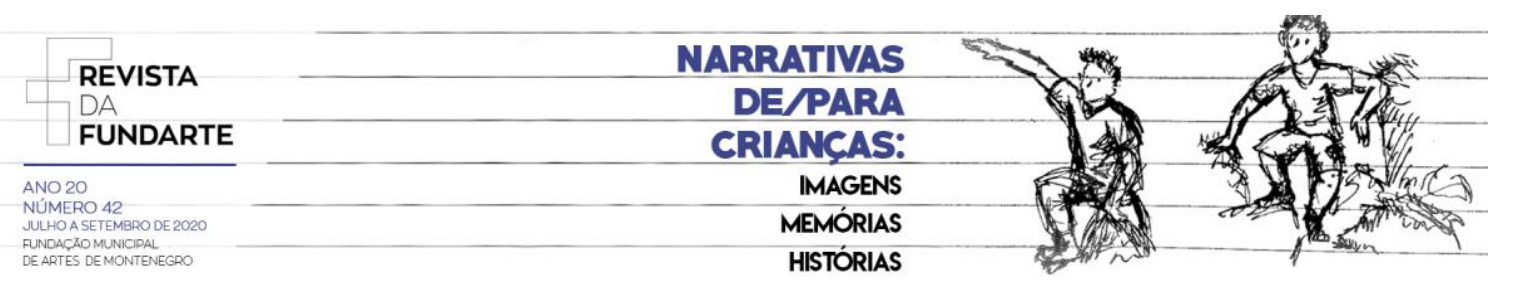

d'enseigner les aspects grammaticaux de la langue. L'univers des textes poétiques augmente l'imaginaire et va au-delà de la compréhension superficielle et normalisée, comme toute ouvre d'art suggère.

Mots clés: Enfant; Professeur; Texte litéraire.

Há muito tempo, os debates sobre o trabalho com a literatura infantil na escola vêm ocupando espaço expressivo nos meios acadêmicos, mediáticos e na esfera educacional. Trata-se, portanto, de tema não negligenciável, no que tange o desenvolvimento das dimensões emocional, social e cognitiva de nossos pequenos aprendizes. Embora tal assertiva seja inquestionável, vivências, observações e verificações indicam uma resistência considerável na adoção e no consumo da literatura como fonte inesgotável de prazer, priorizando-se, ainda, o trabalho com textos literários conduzido sob o pretexto da apropriação dos conteúdos gramaticais da língua materna, desvirtuando sua razão de ser. Literatura é arte e como tal deve ser vivenciada, sentida, sem imposição.

O trabalho com a literatura implica o envolvimento daquele que vai desenvolvê-la em sala de aula. Só se consegue passar ao aluno a enormidade de sensações, de encantamento e de descobertas contidos nos textos literários, se o professor tiver uma história de relação íntima com a literatura.

O potencial criativo dos pequenos é latente e imensurável; manifesta-se de forma espontânea e independente de interferências. Porém, se houver estímulo, mediação e trabalho sistemático, na oferta de amplo material literário - seja para gerar reflexão ou para o simples deleite - o processo de criação será significativamente mais profícuo.

São nítidos o interesse e o envolvimento das crianças ao se depararem com um professor que as conduza a vivenciar os textos literários de forma sistemática, sem relegá-los a raros momentos ou como preenchimento de horários. E, acima de tudo, que esse docente seja um leitor contumaz, que tenha sensibilidade e bom senso para selecionar as obras e extrair delas o prazer, as descobertas e não confundir ou substituir a leitura fruição pela obrigação de preencher fichas sobre o texto lido, o quê, certamente, afastará os pequenos leitores do tão decantado "gosto" pela leitura. Portanto, ela deveria ter no cotidiano escolar um espaço garantido em que professor e alunos mergulhassem 


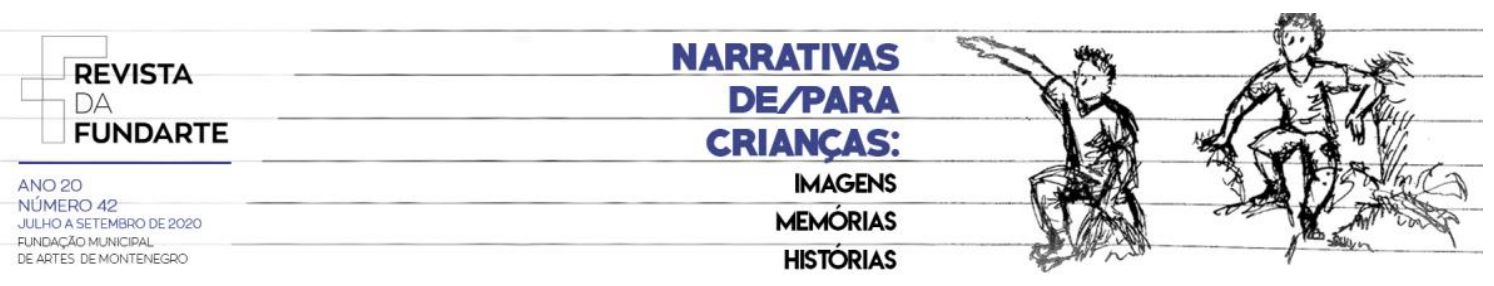

no mundo do imaginário, da fantasia, da ficção, sem o compromisso de tirar dessas leituras ensinamentos referentes aos aspectos gramaticais da língua.

As normas e as regras no que tange a leitura literária podem desencantar, matar na origem o prazer, o interesse, o desejo de ler. Nesse sentido, a afirmativa de Morais é procedente:

\begin{abstract}
Devemos realmente exigir da criança que compreenda - à nossa maneira - o texto que lê, antes de sentir prazer na leitura? Se ela compreende o texto de maneira diferente da nossa, não é necessariamente porque se engana ao decodificar os signos gráficos, mas, muitas vezes, porque as palavras lidas ativam um universo mental, conhecimentos e processos de raciocínio que não correspondem exatamente aos nossos. (Morais, 1996, p.15).
\end{abstract}

A criança, ao apreciar uma história, manifesta a vontade de ouvir ou ler o mesmo texto repetidas vezes ou, simplesmente, deixá-lo de lado, caso não lhe apeteça, portanto, trata-se de uma relação afetiva. E como afirma Morais "[...] o texto transforma-se em ser vivo. Ele respira, transpira, aceita ser lido ou se recusa. Ele nos envolve" (MORAIS, 1996, p.13).

Entre as inúmeras assertivas de Pennac (1992), a que se refere à "gratuidade" nos parece, particularmente, oportuna: "[...] Não se exigia nada, nessa viagem, sequer a menor contrapartida. Lá, tudo se passava como se fosse o país da gratuidade. A gratuidade, que é a única moeda da arte” (p. 38, tradução nossa). Encontra-se aí a sedução da literatura: proporcionar o deleite, sem o compromisso de retorno.

Ainda bem pequenas, as crianças se interessam e se sentem atraídas pelas formas, cores, imagens que os livros apresentam; ao identificá-las, atribuem significados a elas. Assim, desenvolvem de forma gradativa o pensamento lógico e a imaginação e, de acordo com Vigotsky (1992, p. 128), os dois caminham juntos: "a imaginação é um momento totalmente necessário, inseparável do pensamento realista".

Diante do exposto, é importante que o professor propicie a vivência literária aos alunos desde o início da escolaridade, propiciando-lhes um ambiente acolhedor e um 'clima' de liberdade (fácil e frequente acesso aos livros de literatura), oportunizando as trocas, os empréstimos de livros, bem como a abertura de espaço e tempo para os comentários e sugestões, ofertando diferentes e variadas obras. Antecipar o tema a ser 


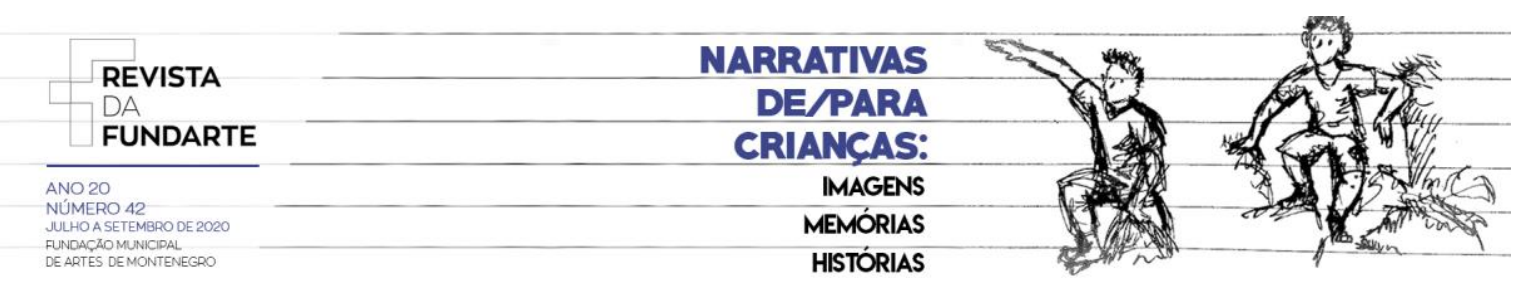

lido, a partir de questionamentos sobre os elementos da capa, instigam a imaginação e geram interesse sobre o assunto. As palavras de Soares corroboram o exposto:

É função e obrigação da escola dar amplo e irrestrito acesso ao mundo da leitura, e isto inclui a leitura informativa, mas também a leitura literária; a leitura para fins pragmáticos, mas também a leitura de fruição; a leitura que situações da vida real exigem, mas também a leitura que nos permita escapar por alguns momentos da vida real. (SOARES, 2008, p. 33).

Para além dos aspectos supramencionados, atribuir os créditos a quem de direito é indispensável e obrigatório. Logo, ao apresentar uma obra, há que se fazer menção ao autor e ao ilustrador, à editora, ao local e ao ano de publicação. A atenção a tais componentes é de fundamental importância ao se trabalhar com textos e livros de diferentes gêneros ou tipos.

Ilustramos com uma situação em que a professora de uma escola pública de Curitiba (Paraná/Brasil), apresenta um livro, mostrando, inicialmente, apenas a capa, de forma a gerar nos alunos, do segundo ano do Ensino Fundamental I, interesse e curiosidade pela história a ser lida (antecipação). O livro em questão é de um autor brasileiro reconhecido e apreciado por leitores mirins, mas atinge todas as faixas etárias. Além de autor do texto escrito, ele produz personagens e cenários com massa de modelar.

A partir da capa, as crianças fazem questionamentos, debatem, formulam hipóteses, expressam opiniões a respeito do possível assunto a ser tratado na obra.

Vejamos, as ideias expostas por alguns alunos:

- É uma história sobre um passarinho, professora.

- Não! É sobre avião. O homem vai viajar...

- Vai viajar em um avião de papel???

- Sim, na história, pode.

Professora:

- Observem com atenção, tudo o que tem na capa do livro.

Alunos:

- O homem é tão pequeno! Ele quase desaparece na capa.

- Tem um livro, também!

ASINELLI, Thania Teixeira. A criança e o texto literário. Revista da FUNDARTE. Montenegro, p.01-16, ano 20, no 42, julho/setembro de 2020.

Disponível em: http://.seer.fundarte.rs.gov.br/index.php/RevistadaFundarte/index> 30 de setembro de 2020. 


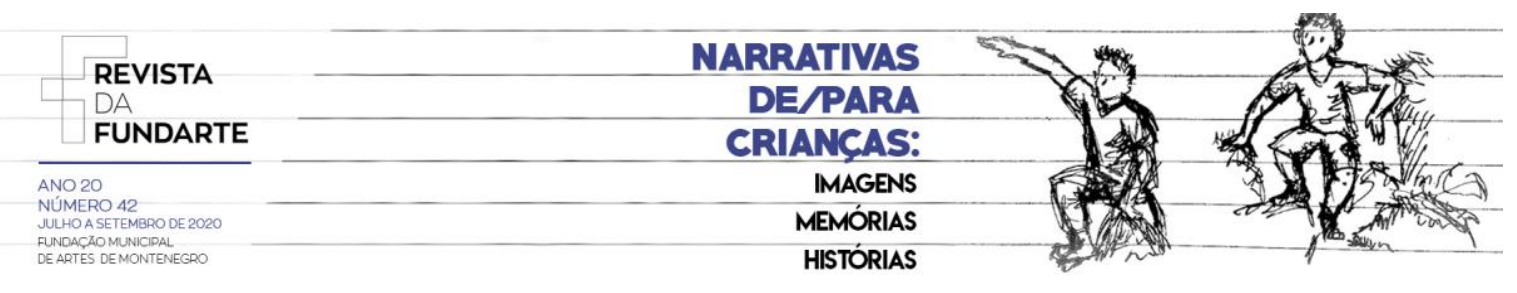

- Ah! E tem o nome do livro e do autor.

Professora:

- O que mais? E sobre a ilustração? O que vocês pensam?

Alunos:

- Tem o nome da editora.

- É um livro ou é uma asa de pássaro?

- A história é sobre o livro? Sobre ler?

- Parece que o homem não é desenhado...

- De que ele é feito, então?

- Vejam como o nome do autor foi escrito! De cima para baixo!

- É bem colorido!

- Professora, leia, por favor!

Então a professora lê a história, mostrando cada página, demoradamente, para toda a turma. Na sequência, a docente solicita que, oralmente, expressem suas ideias, propiciando a todos a revisão das hipóteses iniciais e, solicitando que registrem por escrito as passagens que mais apreciaram no livro. A professora sugere que façam desenhos sobre a história.

Nos dias subsequentes, docente e turma continuam a realizar atividades sobre 0 livro lido: painel com desenhos (equipes de 4 ou 5 crianças); transformação da história em outro gênero textual (poema); produção coletiva de relato sobre o trabalho realizado; carta para o autor da obra.

Encaminhamentos dessa natureza se inserem, inicialmente, em uma ação coletiva, em que as trocas são compartilhadas. A criança se sente acolhida; a professora e o grupo Ihes conferem segurança. Dessa forma, pode-se, sem constrangimento, expor ideias, manifestar sentimentos e opiniões e, então, sentem-se capazes de realizar, individualmente, uma produção escrita, por exemplo. A passagem dessa sensação de pertencimento para o exercício da autonomia e da independência ocorre sem dificuldade, pois "as relações dialógicas ampliam as possibilidades de desenvolvimento dos sujeitos e esta questão já se impõe desde os primeiros processos de escuta e resposta." (CORSINO, 2017, p. 118).

Daí, a enorme responsabilidade da instituição escolar e dos docentes, que ultrapassa as questões normativas do ensinar a ler e escrever, aquisições fundamentais

ASINELLI, Thania Teixeira. A criança e o texto literário. Revista da FUNDARTE. Montenegro, p.01-16, ano 20, no 42, julho/setembro de 2020.

Disponível em: http://.seer.fundarte.rs.gov.br/index.php/RevistadaFundarte/index> 30 de setembro de 2020. 


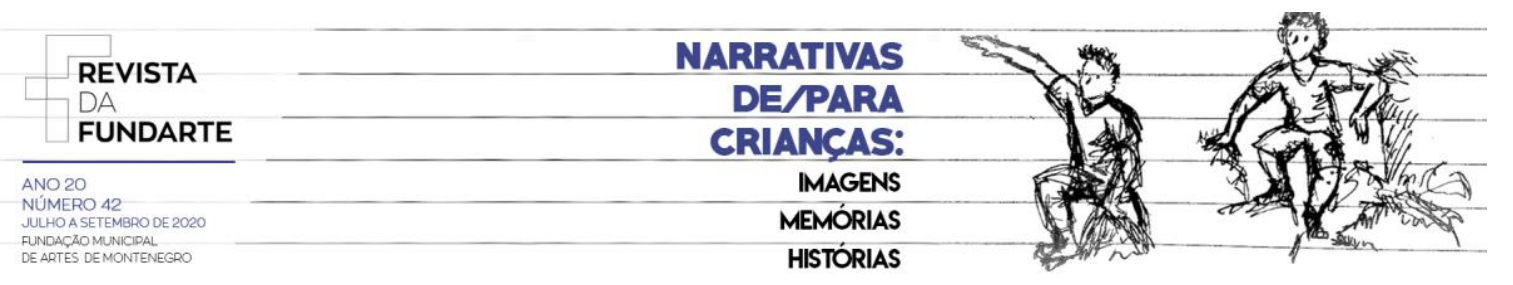

desde que tenham sentido, que sua função seja a de se perceber como sujeito e agente, como partícipe e transformador da realidade. E, ainda, que a leitura e a escrita sirvam para as buscas e descobertas, para a apreciação do senso estético, para um eventual distanciamento dessa realidade, o que, certamente, contribuirá para melhor entendê-la.

Sabe-se que muito do aqui abordado é recorrente, porém, como educadores persistimos na crença de que a literatura merece exercer papel de protagonista no cotidiano das crianças. Famílias, sistema educacional e professores teriam de reforçar o entendimento que essa adesão é capaz de (re)construir a dimensão humana.

\section{Revisitando a poesia: produção da criança como resultado da interação com textos poéticos}

No tocante ao texto poético, verifica-se certo distanciamento entre os leitores e esse gênero textual. Pode-se inferir que a dificuldade reside, frequentemente, na incompreensão, ou ainda, na pretensão de atribuir sentido a uma produção que pode prescindir de nexo.

A recepção dos alunos ao texto literário, tratando-se aqui de poema, requer do professor o trabalho com uma gama variada desse gênero textual, debruçando-se sobre a seleção criteriosa de obras e de diferentes autores que, no Brasil, são incontáveis: Cecília Meireles, Vinícius de Moraes, Bartolomeu Campos Queirós, Roseana Murray, Ruth Rocha, José Paulo Paes, Ana Maria Machado, Sérgio Caparelli, Eva Furnari, entre tantos outros, que imprimem ao texto poético um universo de musicalidade, de encantamento, do jogo cuidadoso com as palavras. Ilustradores, igualmente hábeis, além de complementar os textos escritos, conferem a eles imagens, muitas vezes, tão ou mais eloquentes do que as palavras, ampliando o imaginário, a fantasia e o deleite dos pequenos leitores. De acordo com Palo e Oliveira, os personagens são "seres de papel que habitam o imaginário do livro e se transformam em lances vivos para outras formas de pensamento no instante mágico da leitura". (Palo; Oliveira, 2006, p. 18). 


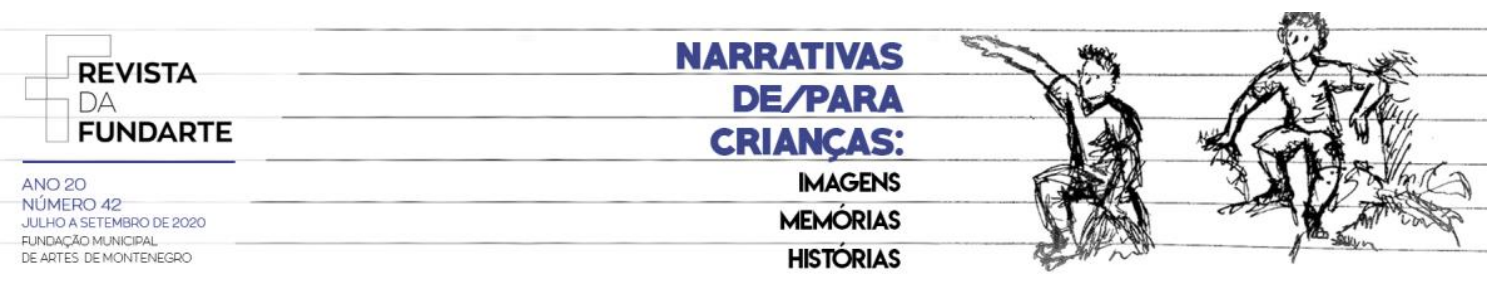

Ouvir um poema lido com cadência, ritmo e entonação adequados faz com que o ouvinte vivencie a experiência dos personagens, que se transporte à cena da ficção, que experimente sensações, sons, texturas... "A poesia, portanto, mesmo quando lida em voz alta afetará o ouvinte opticamente; ele não se aterá à palavra que ouve, mas ao signo de que se lembra, e com ele, às visões que o signo claramente aponta". (ARENDT, 2010, p. 121).

As características do poema, ao contemplarem o senso estético, escapando dos estereótipos, dos clichês e dos pretensos ensinamentos, atingem o nível de obra de arte. Assim, "o estético supera a tecnicidade dos meios e dos instrumentos, portanto, é hedonista e, ao mesmo tempo, perene" (ASINELLI, 2016, p. 5).

No trabalho com o texto poético, o professor tem um papel capital, ao levar a criança a exercer também o papel de mediador entre a ficção e a realidade, entre o que ela criativamente imagina e o mundo ao qual, às vezes, é necessário se abstrair. No entanto, como assinala Cervera:

\begin{abstract}
O educador não tem que ser poeta, mas há de deixar transparecer seu gosto pela poesia e conhecimentos significativos sobre ela. Tampouco há que aspirar que as crianças sejam poetas. Bastará que a influência da poesia alcance a sua sensibilidade mais que o seu pretendido trabalho criativo; bastará que descubram o poder do som das palavras na organização do discurso; bastará, inclusive, que intuam que existem diferenças entre a linguagem da prosa e da poesia .(CERVERA, 1992, p. 91).
\end{abstract}

Um adendo: a respeito do trecho acima citado, convém sinalizar que a 'poesia' pode estar inserida em diferentes gêneros textuais. Pode haver poesia na prosa. Os textos podem estar carregados de intenção estética em suas narrativas, seja um conto ou uma crônica, por exemplo. Poema é a forma de expressar a poesia: sua estrutura, sua organização em versos, podendo ou não conter rimas ou ser apresentado em estrofes.

Embora perceba-se expressiva resistência na aceitação e na lida com textos poéticos (como mencionado anteriormente), há projetos particularmente importantes que merecem crédito. Há diversas escolas cujos professores se dedicam à leitura de poemas com os alunos, de forma a instalar o envolvimento e o desejo de ler e de se servir desse gênero como fonte de prazer e estímulo à criação. 


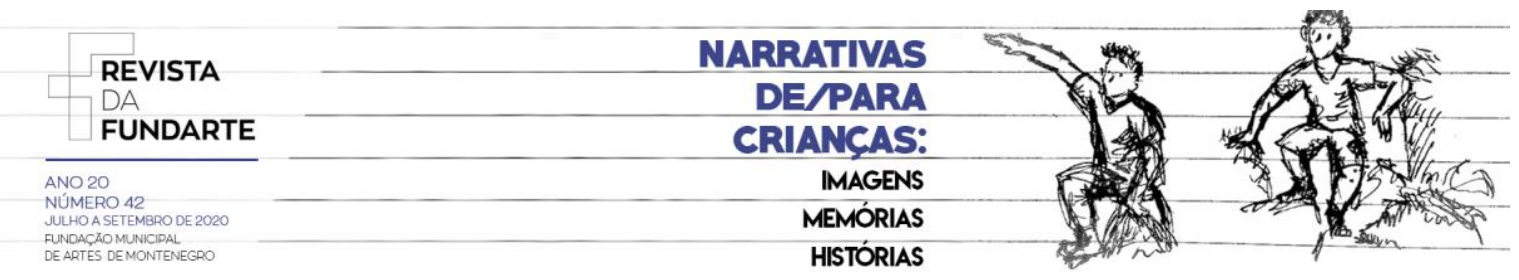

Não são recentes as produções realizadas no Estado do Paraná (Brasil), exemplo que adotamos aqui, e que ocorrem, igualmente, em outros estados brasileiros. Entre muitas experiências realizadas com textos poéticos, seguem alguns exemplos de produção de alunos, a partir de muitas leituras de autores poetas consagrados e atraentes ao público infantil. Salientemos que não apenas os pequenos se sentem atraídos por esse elenco.

O trabalho realizado gerou um pequeno livro autoral de crianças do Ensino Fundamental I de uma escola pública estadual da cidade de Curitiba ( $1^{\circ}$ ao $5^{\circ}$ ano, cuja escola é citada ao final de cada produção):

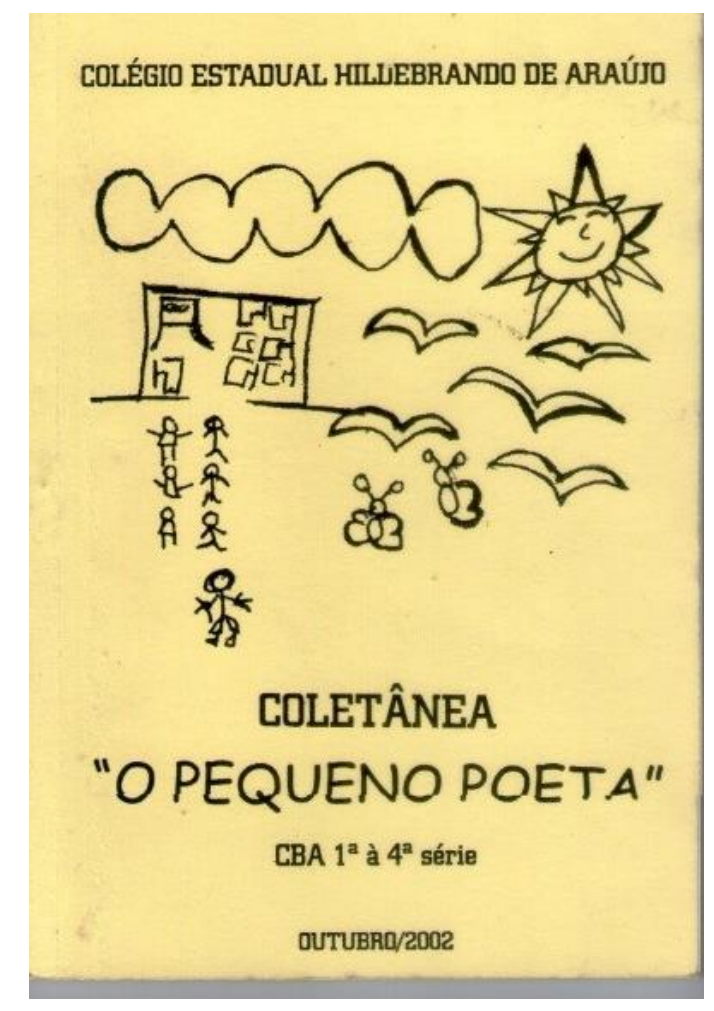

lustração 1: Capa do livro "O pequeno poeta". Fonte: Coletânea "O pequeno poeta": CBA 1ª̀ $4^{\mathrm{a}}$ série. Colégio Estadual Hildebrando de Araújo, 2002. 


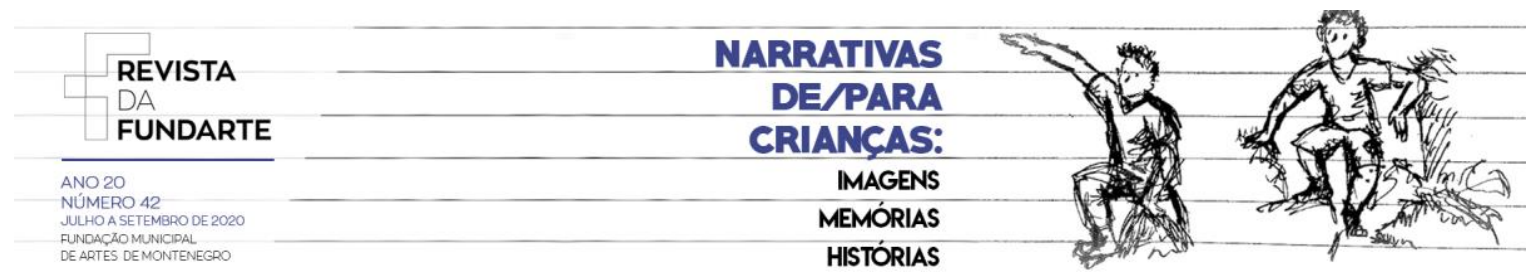

Vejamos as duas produções que seguem: a primeira, Amizades, foi realizada coletivamente e a segunda, Brincadeira, trabalho individual, como resultado das experiências vivenciadas em sala de aula, a partir de um poema de Cecília Meireles.

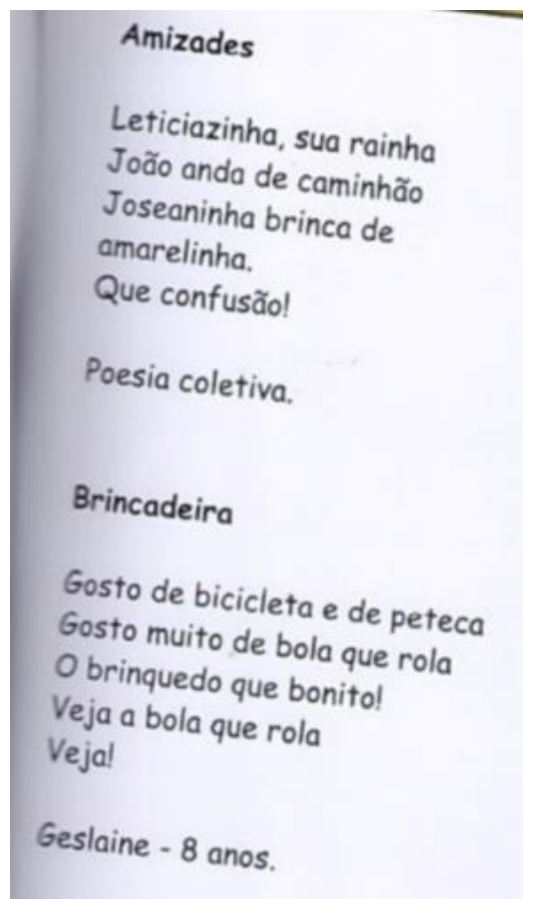

Ilustração 2: Poesia brincadeira (Gislaine, 8 anos). Fonte: Coletânea "O pequeno poeta": CBA 1ª a 4ª série. Colégio Estadual Hildebrando de Araújo, 2002.

\section{Jogo de bola}

A bela bola
rola:
a bela bola do Raul.

Bola amarela a da Arabela

A do Raul, Azula

Rola a amarela e pula a azul.

A bola é mole, é mole e rola.

A bola é bela, é bela e pula. 


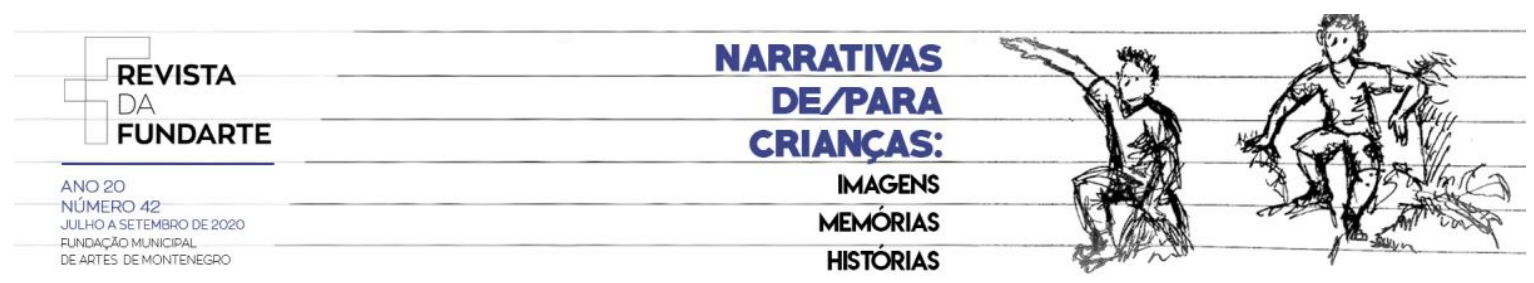

... bela, rola e pula,

É mole, amarela, azul.

A de Raul é de Arabela,

e a de Arabela é de Raul.

(Cecília Meireles, 2012)

No poema Brincadeira (llustração 2), a aluna manteve o tema do texto poético original, acrescentando outras modalidades como peteca e bicicleta. Simplificou a produção, provavelmente, pelo repertório limitado e/ou pela falta de domínio na escrita. Entretanto, demonstrou criatividade e destreza: não empregou rimas, pois sabe que há poemas que podem dispensá-las.

Gradativamente, a partir do trabalho sistemático com textos poéticos, as crianças adquirem e desenvolvem a consciência fonológica, nesse caso, a repetição de sons (aliteração em $b$ e em $r$ ) que Cecília Meireles emprega, conferindo ao poema musicalidade, ritmo e cadência.

A paródia que segue teve como referência o poema Convite, de José Paulo Paes:

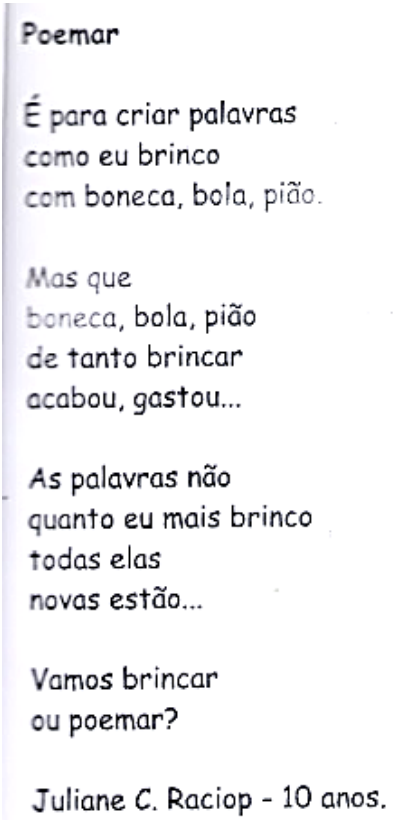

Ilustração 3: Poemar (Juliane C. Rociop, 10 anos). Fonte: Coletânea "O pequeno poeta": CBA 1ª a $4^{\mathrm{a}}$ série. Colégio Estadual Hildebrando de Araújo, 2002. 


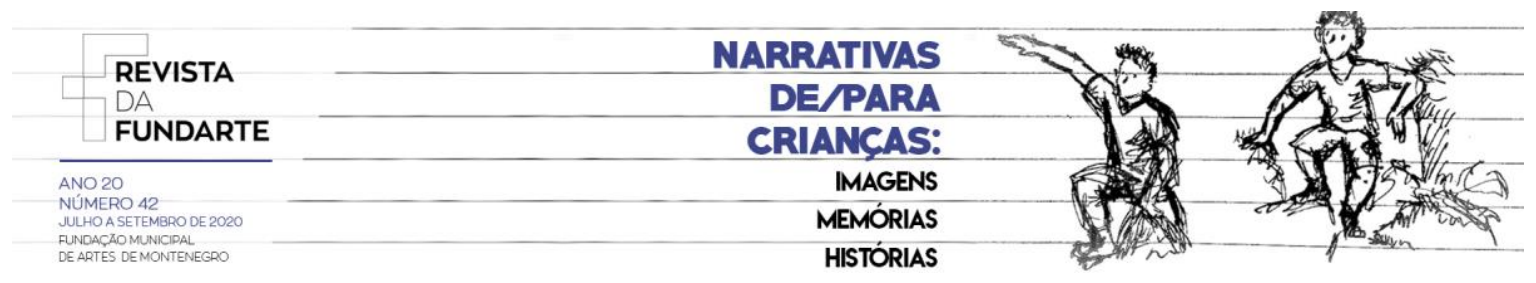

Poema de José Paulo Paes:

Convite

Poesia

é brincar com palavras

como se brinca

com bola, papagaio, pião.

Só que

bola, papagaio, pião

de tanto brincar

se gastam.

As palavras não:

quanto mais se brinca

com elas

mais novas ficam.

Como a água do rio

que é água sempre nova.

Como cada dia

que é sempre um novo dia.

Vamos brincar de poesia?

(Paes, 1990, p. 3)

Juliane usou, de forma espontânea, um neologismo no título do poema, demonstrando habilidade na criação de uma nova palavra: Poemar. Ao final do texto, a aluna contrapõe o brincar ao poemar escapando da ideia original de José Paulo Paes.

ASINELU, Thania Teixeira. A criança e o texto literário. Revista da FUNDARTE. Montenegro, p.01-16, ano ASINELLI, Thania Teixeira. A criança e o texto literário. Revista da FUNDARTE. Montenegro, p.01-16, ano 20, no 42, julho/setembro de 2020.

Disponível em: http://.seer.fundarte.rs.gov.br/index.php/RevistadaFundarte/index> 30 de setembro de 2020. 


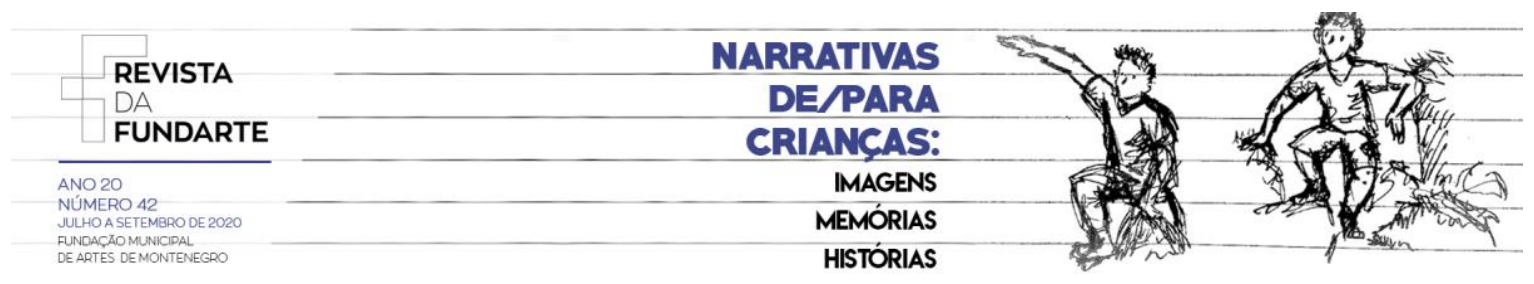

Afinal, fazer uma releitura e criar, a partir de um texto dado, requer originalidade sem, contudo, prescindir do tema.

Ary Barroso criou Aquarela do Brasil em 1939, canção que exalta os atributos do país e é considerada a mais importante composição desse autor. No texto poético, a seguir, o aluno Diego (10 anos) parodia essa canção.

\section{Meu Brasil}

Brasil

meu Brasil, brasileiro

Tu és um guerreiro

Brasil!

Brasil

Você é um dos melhores

países

deixa de crises.

Tu és muito belo

Brasil!

Brasil

Você é minha Pátria

Amada

Brasil tu és forte

e tens muita sorte!!!

Diego Menezes Silva - 10 anos.

Ilustração 4: Meu Brasil (Diego Menezes Silva, 10 anos). Fonte: Coletânea "O pequeno poeta": CBA $1^{\mathrm{a}}$ a $4^{\mathrm{a}}$ série. Colégio Estadual Hildebrando de Araújo, 2002.

Aquarela do Brasil

Ary Barroso

Brasil, meu Brasil brasileiro

ASINELLI, Thania Teixeira. A criança e o texto literário. Revista da FUNDARTE. Montenegro, p.01-16, ano 20, nำ 42, julho/setembro de 2020.

Disponível em: http://.seer.fundarte.rs.gov.br/index.php/RevistadaFundarte/index> 30 de setembro de 2020. 


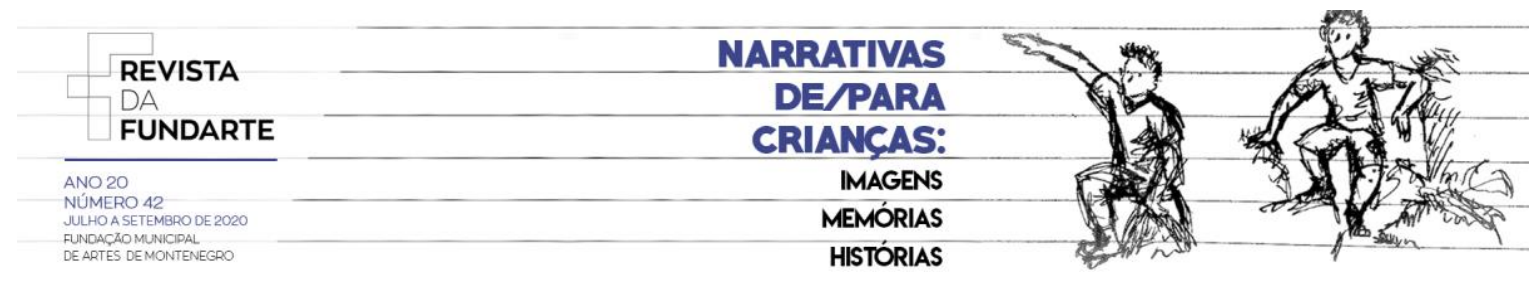

Meu mulato inzoneiro

Vou cantar-te nos meus versos

O Brasil, samba que dá Bamboleio, que faz gingar O Brasil do meu amor Terra de Nosso Senhor Brasil! Brasil! Pra mim! Pra mim!

Ô, abre a cortina do passado Tira a mãe preta do cerrado Bota o rei congo no congado Brasil! Brasil!

Deixa cantar de novo o trovador À merencória luz da lua Toda canção do seu amor Quero ver essa Dona caminhando Pelos salões, arrastando O seu vestido rendado Brasil! Brasil! Prá mim! Prá mim!

Brasil, terra boa e gostosa

Da morena sestrosa

De olhar indiscreto

O Brasil, samba que dá

Para o mundo admirar

O Brasil do meu amor

Terra de Nosso Senhor

Brasil! Brasil! Prá mim! Prá mim!

Esse coqueiro que dá coco

Onde eu amarro a minha rede

Nas noites claras de luar

Ô! Estas fontes murmurantes

Onde eu mato a minha sede

E onde a lua vem brincar

Ô! Esse Brasil lindo e trigueiro

É o meu Brasil brasileiro

Terra de samba e pandeiro

Brasil! Brasil!

Diego repetiu o enaltecimento ao Brasil e acrescentou um elemento de uso recorrente, no país: a crise. Retomou, no seu texto, a ideia da beleza e do amor à pátria, conceitos presentes na canção original e, via de regra, adotados na escola, encorajando 0 civismo, muitas vezes, encaminhado de forma superficial. A análise da letra da canção 20, no 42, julho/setembro de 2020.

Disponível em: http://.seer.fundarte.rs.gov.br/index.php/RevistadaFundarte/index> 30 de setembro de 2020. 


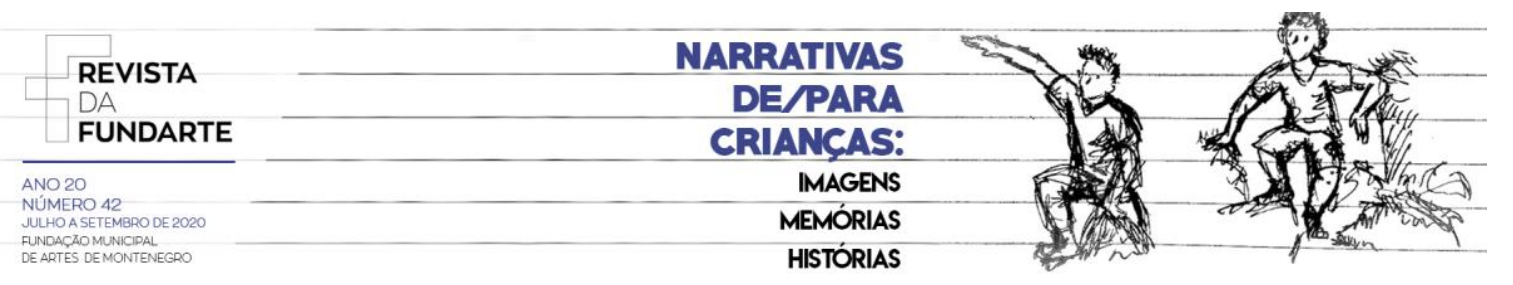

não foi aprofundada pela professora, restringindo-se à estratégia da tarefa: produzir um texto poético à semelhança do original.

\section{Considerações Finais}

A Literatura Infantil, a exemplo do que se observa amiúde nas escolas, está mais voltada a um projeto pedagógico rígido e normatizado ou, no limite, descompromissado com seu real valor e importância. Obras literárias têm uma função própria, portanto, devem ser tratadas a partir de sua particularidade.

Em tempos de expressiva indisponibilidade das famílias, cabe preponderantemente à escola exercer o papel de formadora de leitores literários, seguindo, porém, o viés da recepção de professores e alunos como críticos, que têm interiorizado o conceito da Literatura "como um processo de recepção e produção estética que se realiza na atualização dos textos literários por parte do leitor que os recebe, do escritor, que se faz novamente produtor e do crítico, que sobre eles reflete". (JAUSS, 1994, p. 25).

No que tange a leitura literária, como esperar sentimentos iguais de seres diferentes na essência, na trajetória, no repertório, nas relações que o social Ihes impõe? Inaceitável, porém, mais comum do que se imagina. Menos admissível, ainda, quando a exigência vem de educadores que estipulam interpretações, deixando à margem aquelas que não correspondem ao traçado exatamente na obra ou parecerem distantes e diferentes das ideias preconcebidas do professor.

Entretanto, há que se eximir escolas e professores como os principais responsáveis pela significativa inapetência e/ou inadequação ao trabalho com textos literários, pois lidam seguidamente, com situações pouco favoráveis, por exemplo: grande parte das crianças são advindas de famílias não leitoras. Há que se levar em conta, igualmente, a falta de envolvimento efetivo e oportuno do sistema educacional brasileiro nesse quesito.

As experiências supramencionadas indicam cenários alentadores, no que concerne o trabalho escolar com a literatura infanto-juvenil. Projetos dessa natureza, inserindo 


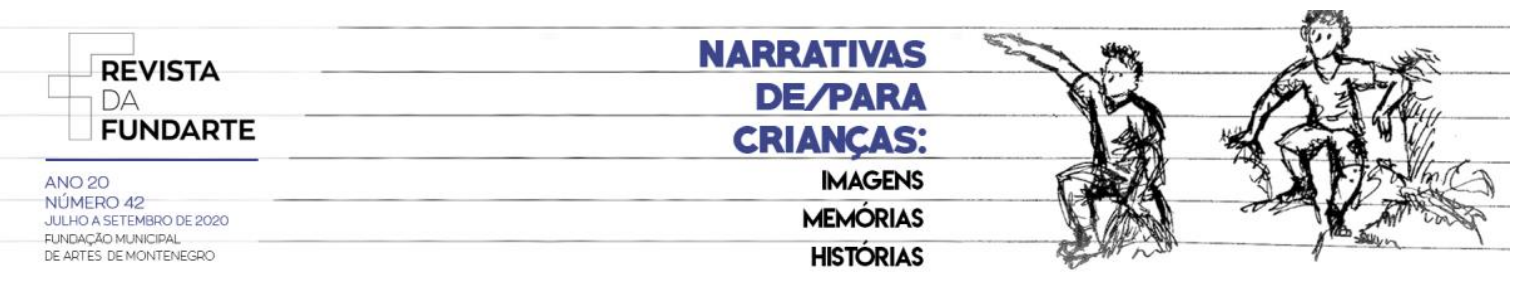

obras abertas às possibilidades de interação, releituras e deleite, atribuem à literatura o protagonismo devido, restabelecendo seu papel no tempo-espaço escolar.

\section{Referências:}

ARENDT, A. A vida do espírito. Rio de Janeiro: Civilização Brasileira, 2010.

ASINELLI, T. Escola e literatura. In: AZEVEDO, F.; SARDINHA, M. G.; OSÓRIO, P.; PAIS, A. (Coord.). Elementos de didática da língua e da literatura em contexto pedagógico. Braga: CIEC Universidade do Minho, 2016.

CERVERA, J. Teoria de la literatura infantil. Bilbao: Universidad de Deusto/ Ediciones Mensajero, 1992.

CORSINO, P. Infância, linguagem e literatura: reflexões para a educação infantil. In: NOGUEIRA, A.N.; FRISZMAN, A.L. (Org.). Leitores e leituras. São Paulo: Leitura Crítica, 2017.

JAUSS, H. R. A história da literatura como provocação à teoria literária. São Paulo: Ática, 1994.

MEIRELES, C. Ou isto ou aquilo. 7. ed. São Paulo: Global, 2012.

MORAIS, J. A arte de ler. São Paulo: Unesp, 1996.

PAES, J. P. Poemas para brincar. São Paulo: Ática, 1990.

PALO, M. J.; OLIVEIRA, M. R. D. Literatura infantil: voz de criança. 4. ed. São Paulo: Ática, 2006.

PENNAC, D. Comme un roman. Paris: Gallimard, 1992.

SOARES, M. Ler, verbo transitivo. In: PAIVA, A.; MARTINS, A.; PAULINO, G.; VERSIANI, Z. (Orgs.). Leituras literárias: discursos transitivos. Belo Horizonte: Ceale, Autêntica, 2008.

VYGOTSKY, L. S. O desenvolvimento psicológico na infância. São Paulo: Martins Fontes, 1992. 